\title{
Filme plástico perfurado em túneis baixos cultivados com alface
}

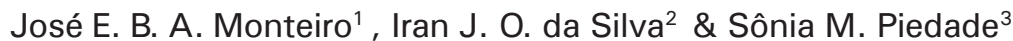

1 ESALQ/USP. Av. Pádua Dias 11, CEP 13416-090, Piracicaba, SP. Fone: (19) 429-4217. E-mail: eduardo@esalq.usp.br (Foto)

2 Departamento de Engenharia Rural/NUPEA. E-mail: ijosilva@esalq.usp.br

${ }^{3}$ Departamento de Ciências Exatas, ESALQ/USP. E-mail: soniamsp@esalq.usp.br

Protocolo $21-21 / 2 / 2001$

\begin{abstract}
Resumo: O objetivo deste trabalho foi avaliar as condições micrometeorológicas no interior de túneis baixos cultivados com alface, através da perfuração do filme plástico, técnica utilizada para melhorar a ventilação no interior dos túneis, porém ainda pouco conhecida. Assim, foram testados túneis sem e com cultura de alface, com 0,5, 10, 15 e $20 \%$ de área de filme perfurada e, também, um canteiro sem túnel, durante a primavera. As variáveis meteorológicas utilizadas para a avaliação dos tratamentos foram temperatura e umidade relativa do ar, verificando-se que, quanto maior o percentual de perfuração, menor a elevação da temperatura no interior do ambiente protegido e maior a perda de umidade para o ambiente exterior. A produção obtida nos ambientes protegidos foi maior e de melhor qualidade.
\end{abstract}

Palavras-chave: Lactuca sativa L., plasticultura, microclima

\section{Perforated plastic film for low tunnels cultivated with lettuce}

\begin{abstract}
The present work was carried out with the objective to evaluate the micrometeorological conditions inside low tunnels cultivated with lettuce. A technique used to improve the ventilation inside the tunnels is the perforation of the plastic film, though still not very well known. Therefore, tunnels were tested without and with lettuce crop, with 0,5, 10, 15 and $20 \%$ of perforated film area and in soil without tunnel, during spring. The meteorological variables used for the evaluation of the treatments were temperature and relative humidity of air. It was verified that the elevation of the temperature inside the protected atmosphere was inversely related to percentage of perforation contrary to the humidity loss for the external atmosphere. The production obtained under protected conditions was higher and of better quality.
\end{abstract}

Key words: Lactuca sativa L., low tunnel, plasticulture, microclimate

\section{INTRODUÇÃO}

Com o surgimento do plástico e o aperfeiçoamento da sua utilização no meio agrícola, foi possível obter-se grandes avanços na produção de alimentos, visto que uma de suas utilizações é fazer parte de estruturas de proteção aos canteiros cultivados como, por exemplo, de túneis baixos. A falta de conhecimento sobre os aspectos estruturais, geometria e forma que determinam a dinâmica dos fatores ambientais, como temperatura, umidade e luminosidade no interior dos túneis, inviabiliza o dimensionamento de estruturas que proporcionem um microclima mais favorável ao desenvolvimento das plantas.

De acordo com Buriol et al. (1993), a temperatura do ar pode elevar-se muito em dias de intensa radiação solar, necessitando de muito rigor em seu manejo sendo importante tanto o momento como a magnitude de sua abertura, esta uma das características importantes, pois não apresenta informações consistentes relacionadas à ambiência dos túneis.

Segundo Sganzerla (1995) a utilização do plástico perfurado em túneis de cultivo forçado é recente e mais conhecida no Japão, Estados Unidos e França. Este sistema permite que a ventilação ocorra através das perfurações, reduzindo a necessidade de manejo das laterais para o arejamento do ambiente, muito importante para evitar temperaturas e umidade excessivas, prejudiciais ao desenvolvimento de hortaliças.

Assim, como não há resultados experimentais do uso desta técnica em condições meteorológicas similares às de Piracicaba, SP, o objetivo deste trabalho foi avaliar o ambiente no interior de túneis baixos com filme plástico perfurado e o seu desempenho como condicionador do rendimento de alface, na referida região. 


\section{MATERIAL E MÉTODOS}

O experimento foi conduzido junto ao Núcleo de Pesquisas em Ambiência, Campus "Luiz de Queiroz", Universidade de São Paulo, Piracicaba, SP, clima Cwa, segundo a classificação de Köppen, chuvoso no verão e seco no inverno (latitude: $22^{\circ} 42^{\prime} 40^{\prime}$ ' S, longitude: $47^{\circ} 37^{\prime} 30^{\prime}$ 'W, altitude: $550 \mathrm{~m}$ ).

Em cinco canteiros, o solo foi preparado e destorroado a $0,25 \mathrm{~m}$ de profundidade com enxada rotativa e depois adubado de acordo com os resultados da análise de solo. Cada canteiro foi coberto com polietileno transparente de baixa densidade (PEBD) em forma de túneis baixos de 1,2 $\mathrm{m}$ de largura, 6,0 $\mathrm{m}$ de comprimento e $0,6 \mathrm{~m}$ de altura, e um canteiro sem cobertura, todos dispostos no sentido Leste-Oeste.

A variedade de alface utilizada foi a "Verônica", do grupo "Solta Crespa", cultivada no espaçamento 0,3 x 0,3 m. As plântulas foram transplantadas para os canteiros com cerca de 4 a 5 folhas definitivas, cerca de 20 d após a semeadura, no dia 29 de setembro, e colhidas no dia 7 de novembro de 2000 , quando algumas plantas começavam a apresentar sinais de pendoamento.

Desta forma, foram estudados seis diferentes tratamentos, que se seguem: $\left(T_{1}\right)$ canteiro sem cobertura, a céu aberto; $\left(T_{2}\right)$ túnel baixo com $20 \%$ de área de filme perfurada; $\left(\mathrm{T}_{3}\right)$ túnel baixo com $15 \%$ de perfuração; $\left(\mathrm{T}_{4}\right)$ com $10 \%$ de perfuração; $\left(\mathrm{T}_{5}\right)$ com $5 \%$ de perfuração e $\left(\mathrm{T}_{6}\right)$ túnel baixo sem perfuração, $0 \%$.

Os canteiros foram divididos no comprimento em 4 subáreas de 1,5 m, abrigando 20 plantas cada. Para fins de análise estatística, cada subárea foi considerada como uma repetição de cada tratamento e o delineamento experimental utilizado foi o de blocos ao acaso.

As perfurações foram distribuídas uniformemente e eqüidistantes, de forma circular e com $10 \mathrm{~mm}$ de diâmetro. Utilizouse em cada tratamento, um termohigrômetro localizado no centro do túnel a 0,3 $\mathrm{m}$ de altura, protegido da incidência direta de radiação solar, que forneceu os dados relativos à temperatura do ambiente e umidade relativa do ar. A coleta de dados meteorológicos foi realizada das 8 às $18 \mathrm{~h}$ de 22 a 31 de outubro de 2000, fase em que as plantas já cobriam praticamente toda a área dos canteiros. $\mathrm{O}$ delineamento estatístico utilizado para a análise dos dados meteorológicos foi o de blocos ao acaso. Neste caso, cada dia de coleta de dados corresponde a um bloco.

\section{RESULTADOS E DISCUSSÃO}

Em todos os canteiros protegidos com túnel, a temperatura média diária e a umidade relativa foram sempre maiores que no canteiro sem cobertura devido, principalmente, ao pequeno volume de ar contido no interior dos túneis, que está menos sujeito à renovação que no ambiente externo. A cobertura plástica minimizou a transferência de energia na forma de calor latente e sensível, além de conter as movimentações advectivas de ar. Isto se confirma ao se analisar as diferenças observadas entre os tratamentos. Os ganhos térmicos foram maiores à medida em que a área perfurada foi menor (Monteiro et al., 2001b), atingindo o máximo no túnel sem perfuração e o mínimo no canteiro sem túnel, conforme a Figura 1, evidenciando que, de fato, a perfuração do plástico aumentou a ventilação intratúnel.

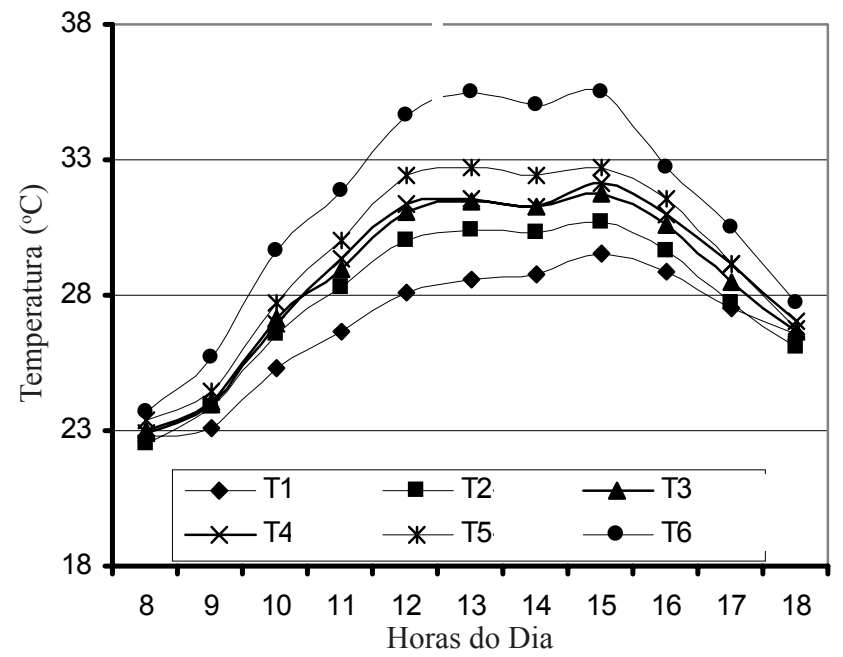

Figura 1. Temperatura média do ar durante os dias selecionados para análise de dados entre 8 e $18 \mathrm{~h}$ no interior dos túneis baixos de polietileno transparente com $0\left(\mathrm{~T}_{6}\right), 5\left(\mathrm{~T}_{5}\right), 10\left(\mathrm{~T}_{4}\right)$, $15\left(\mathrm{~T}_{3}\right)$ e $20 \%\left(\mathrm{~T}_{2}\right)$ de área perfurada e, solo nú sem túnel $\left(\mathrm{T}_{1}\right)$

Em trabalho similar realizado nas condições de Santa Maria, RS, região mais fria que Piracicaba, SP, Buriol et al. (1993) observaram tendência semelhante, porém testaram áreas de perfuração menores, de 0,78 a 3,14\%, as quais se mostraram adequadas às condições.

No ambiente limitado pelo túnel sem perfuração, a temperatura atingia valores elevados para o cultivo da alface e, mesmo nos túneis perfurados, durante as horas mais quentes do dia, a temperatura normalmente excedia os $30^{\circ} \mathrm{C}$ (Fig. 1).

De acordo com Scarpare Filho (1995), devido ao processo fotossintético da maioria das plantas cultivadas, a temperatura ótima para o desenvolvimento vegetativo é cerca de $25{ }^{\circ} \mathrm{C}$. À medida que a temperatura varia, alcançando valores muito diferentes dessa média ótima, o crescimento da planta é prejudicado.

Constata-se também um maior efeito da cobertura plástica sobre as temperaturas máximas (Fig. 1). Em seus estudos, Tanaka \& Genta (1982) e Monteiro et al. (2001a), atribuem esse fato à relação da temperatura com radiação solar, ao menor volume de ar a ser aquecido e o efeito do plástico que restringe a ação dos ventos. Manzini (1994) avaliando o emprego do túnel baixo na produção de abobrinha italiana (Cucúrbita pepo var. melopepo) relata que a ocorrência de uma geada de advecção no decorrer do estudo causou a morte das plantas nas parcelas sem túnel, enquanto que as parcelas protegidas com túnel, as plantas não apresentaram danos significativos. Neste caso, destaca-se o efeito do plástico na redução da ação dos ventos frios sobre a cultura.

O solo foi mantido sempre próximo à capacidade de campo. Devido a esta condição foi possível que, mesmo nas horas mais quentes do dia, a umidade relativa do ar não decrescesse muito (Fig. 2) o que é, além da temperatura, decisivo para o desenvolvimento da alface. 


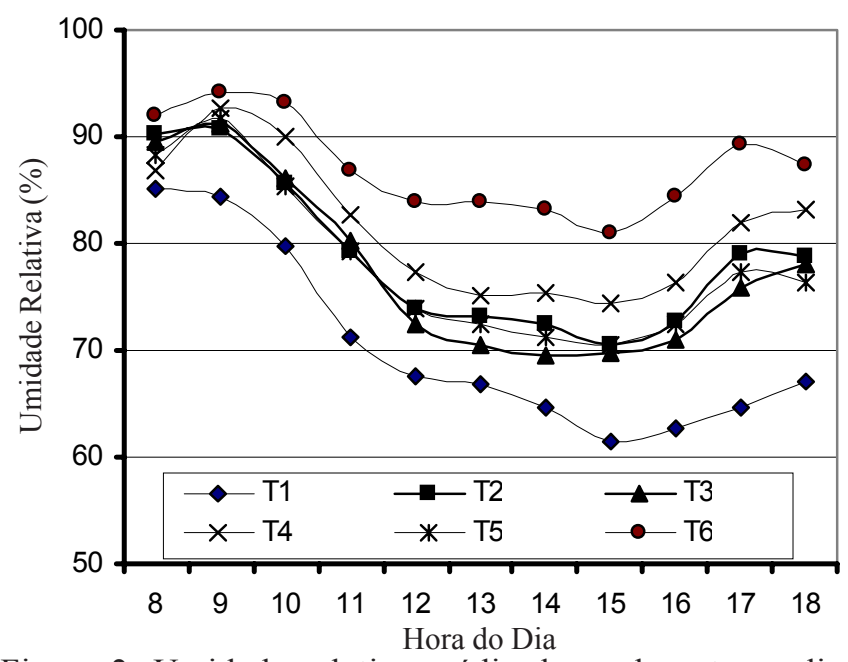

Figura 2. Umidade relativa média do ar durante os dias selecionados para análise de dados entre 8 e 18 h no interior dos túneis baixos de polietileno transparente com $0\left(\mathrm{~T}_{6}\right), 5$ $\left(\mathrm{T}_{5}\right), 10\left(\mathrm{~T}_{4}\right), 15\left(\mathrm{~T}_{3}\right)$ e $20 \%\left(\mathrm{~T}_{2}\right)$ de área perfurada, e solo nú sem túnel $\left(\mathrm{T}_{1}\right)$

Aos 30 dias após o transplantio, a maioria das plantas sob os túneis plásticos já havia excedido o tamanho mínimo do padrão normalmente praticado no varejo para essa variedade. A colheita das plantas se deu aos 40 dias após o transplantio, quando algumas plantas começaram a apresentar sinais de pendoamento.

No período estudado, os resultados dos parâmetros de crescimento, produção de matéria verde, seca, e comprimento do caule, foram mais elevados no interior dos túneis (Tabela 1). Resultados semelhantes foram obtidos por Streck et al. (1994), porém em uma região mais fria e com menores níveis de perfuração.

Tabela 1. Massa de matéria verde (MV), comprimento do caule (CC), teor de matéria seca (TMS) e massa de matéria seca (MS) de plantas de alface cv. Verônica, no momento de colheita, ao final do ciclo, cultivadas no interior de túneis baixos de polietileno transparente sob diferentes tratamentos*

\begin{tabular}{lccrc}
\hline \multicolumn{1}{c}{ Tratamento $^{*}$} & $\begin{array}{c}\text { MV } \\
\left(\text { g planta }^{-1}\right)\end{array}$ & $\begin{array}{c}\text { CC } \\
(\mathrm{cm})\end{array}$ & $\begin{array}{c}\text { TMS } \\
(\%)\end{array}$ & $\begin{array}{c}\text { MS } \\
(\text { g planta }\end{array}$ \\
\hline $\mathrm{T}_{1}$ (s/ túnel) & $180 \mathrm{~b}$ & $17,7 \mathrm{~b}$ & $12,3 \mathrm{a}$ & $22,3 \mathrm{a}$ \\
$\mathrm{T}_{2}(20 \%$ perfu. $)$ & $280 \mathrm{a}$ & $25,8 \mathrm{a}$ & $8,6 \mathrm{~b}$ & $24,0 \mathrm{a}$ \\
$\mathrm{T}_{3}(15 \%$ perfu. $)$ & $325 \mathrm{a}$ & $25,9 \mathrm{a}$ & $8,2 \mathrm{~b}$ & $26,7 \mathrm{a}$ \\
$\mathrm{T}_{4}(10 \%$ perfu. $)$ & $275 \mathrm{a}$ & $26,9 \mathrm{a}$ & $8,9 \mathrm{~b}$ & $24,5 \mathrm{a}$ \\
$\mathrm{T}_{5}(5 \%$ perfu. $)$ & $293 \mathrm{a}$ & $25,3 \mathrm{a}$ & $9,5 \mathrm{~b}$ & $27,7 \mathrm{a}$ \\
$\mathrm{T}_{6}(0 \%$ perfu. $)$ & $285 \mathrm{a}$ & $25,0 \mathrm{a}$ & $8,6 \mathrm{~b}$ & $24,5 \mathrm{a}$ \\
\hline
\end{tabular}

"Médias seguidas pela mesma letra na coluna não diferem estatisticamente pelo teste de Tukey, em nível de $5 \%$ de probabilidade

O teor de matéria seca foi maior no ambiente desprotegido, aproximadamente $12 \%$, contra 8 a $9 \%$ nos demais. A produção total de matéria seca foi $14 \%$ maior nos túneis; já a massa verde foi, em média, $62 \%$ superior nos túneis quando comparados ao canteiro descoberto (Tabela 1). Obviamente, isto se deve à diferença de umidade entre as plantas dentro e fora dos túneis, fato este que infere diretamente sobre a qualidade da produção.
Pereira (2002), avaliando a cultura da rúcula (Eruca vesicaria sativus (Mill) Thell) e do rabanete (Raphanus sativus L.), no mesmo local, com os mesmos tratamentos, observou no verão, produção de matéria seca de rúcula $45 \%$ maior nos túneis do que nas parcelas sem túnel. No inverno, o rabanete apresentou produção de matéria seca $44 \%$ maior nos túneis.

Avaliando-se as plantas qualitativamente, concluiu-se que as que se desenvolveram nos túneis apresentaram-se mais tenras, mais volumosas, maiores e com aspecto sensivelmente superior.

Nos resultados dos túneis perfurados ou mesmo com o túnel sem perfuração, não há diferenças significativas entre comprimento do caule, produção de matéria verde e seca. $\mathrm{O}$ teor de matéria seca foi aproximadamente o mesmo porém apenas a título de inferência, constata-se que a produção de matéria verde no túnel com $15 \%$ de área perfurada foi, em média, $14 \%$ maior que nos demais.

Logo, seria recomendável que a adoção desta técnica em condições semelhantes às apresentadas deveria adotar o percentual de perfuração que se mostrou mais favorável, ou seja, $15 \%$. No entanto, considera-se que o plástico perfurado não apresente variações de preço em função de maior ou menor percentual de área perfurada, o que depende de cada fabricante.

Hortaliças folhosas como a alface, perdem água muito facilmente para o ambiente, através da transpiração. Dependendo da demanda evaporativa da atmosfera no ambiente, a taxa de perda de água pela planta pode ser maior que a taxa de reposição, mesmo em condições de plena disponibilidade de água no solo; assim, as elevadas umidades relativas do ar ocorridas no interior dos túneis contribuem para que as plantas se mantenham sempre túrgidas.

No ambiente desprotegido a umidade relativa atingiu os menores valores, principalmente nas horas mais críticas do dia, caso em que se admitiria, então, que os melhores resultados seriam encontrados no túnel sem perfuração, devido os maiores valores de umidade relativa do ar terem ocorrido nesse ambiente. Por outro lado, embora isto seja certo, a temperatura nesse mesmo tratamento apresentou, também, valores elevados e maiores que a faixa ótima para o desenvolvimento da alface.

Outro fator muito importante, relacionado à umidade do ambiente, é a incidência de vento. As movimentações advectivas de ar, além de contribuírem para a renovação do ar junto ao solo e às plantas, incidem diretamente sobre as folhas, acelerando a perda de água pelas mesmas e, em alguns casos, desidratando folhas mais jovens ou as mais expostas.

Tabela 2. Valores médios* diários de temperatura média (TM), umidade relativa média do ar (URM) e pressão parcial média de vapor de água (PAVM) no interior de túneis baixos de polietileno transparente sob diferentes tratamentos

\begin{tabular}{llll}
\hline \multicolumn{1}{c}{ Tratamento } & $\begin{array}{c}\text { TM } \\
\left({ }^{\circ} \mathrm{C}\right)\end{array}$ & $\begin{array}{c}\text { URM } \\
(\%)\end{array}$ & $\begin{array}{c}\text { PAVM } \\
(\mathrm{kPa})\end{array}$ \\
\hline $\mathrm{T}_{1}$ (s/ túnel) & $26,9 \mathrm{e}$ & $70 \mathrm{c}$ & $2,35 \mathrm{~d}$ \\
$\mathrm{~T}_{2}(20 \%$ perfu. $)$ & $27,8 \mathrm{~d}$ & $79 \mathrm{~b}$ & $2,82 \mathrm{c}$ \\
$\mathrm{T}_{3}(15 \%$ perfu. $)$ & $28,6 \mathrm{~cd}$ & $78 \mathrm{~b}$ & $2,89 \mathrm{bc}$ \\
$\mathrm{T}_{4}(10 \%$ perfu. $)$ & $28,8 \mathrm{bc}$ & $81 \mathrm{~b}$ & $3,12 \mathrm{~b}$ \\
$\mathrm{~T}_{5}(5 \%$ perfu. $)$ & $29,4 \mathrm{~b}$ & $78 \mathrm{~b}$ & $3,08 \mathrm{bc}$ \\
$\mathrm{T}_{6}(0 \%$ perfu. $)$ & $31,1 \mathrm{a}$ & $87 \mathrm{a}$ & $3,90 \mathrm{a}$ \\
\hline
\end{tabular}

" Médias seguidas pela mesma letra na coluna não diferem estatisticamente pelo teste de Tukey, em nível de $5 \%$ de probabilidade 


\section{CONCLUSÕES}

1. A perfuração do filme plástico de cobertura proporcionou significativas alterações nas condições meteorológicas no interior do túnel baixo.

2. Quanto maior o percentual de perfuração, menor a elevação da temperatura no interior do ambiente protegido e maior a perda de umidade para o ambiente externo.

3. O desenvolvimento da alface nas condições climáticas de primavera na região, foi favorecido no ambiente sob os túneis baixos de polietileno transparente perfurado em relação ao ambiente externo.

\section{LITERATURA CITADA}

Buriol, G.A.; Schneider, F.M.; Streck, N.A.; Medeiros, S.L.P. Modificação ambiental causada por túneis baixos de polietileno transparente perfurado cultivados com alface. Ciência Rural, Santa Maria, v.23, n.3, p.261-266, 1993.

Manzini, J.P. Emprego do túnel de cultivo forçado e da cobertura de solo na produção de abobrinha italiana (Cucúrbita papo var. melopepo), em condições de outono-inverno. Jaboticabal, 1994. 54p. Relatório Iniciação Científica
Monteiro, J.E.B.A., Silva, I.J.O., Piedade, S.M.S. Uso de filme plástico perfurado em túneis baixos (I) sem cultura. In: Congresso Brasileiro de Agrometeorologia, 12. 2001, Fortaleza. Anais... Fortaleza, 2001a. p.779-780.

Monteiro, J.E.B.A., Silva, I.J.O., Piedade, S.M.S. Uso de filme plástico perfurado em túneis baixos (II) cultivados com alface (Lactuca sativa L.). In: Congresso Brasileiro de Agrometeorologia, 12. 2001, Fortaleza. Anais... Fortaleza, 2001 b. p.777-778.

Pereira, E.R. Cultivo da rúcula e do rabanete sob túneis baixos cobertos com plástico com diferentes níveis de perfuração. Piracicaba, 2002. 113p. Dissertação Mestrado

Scarpare Filho, J.A. Viveiros para a formação de mudas. In: Minami, K. Produção de mudas de alta qualidade em horticultura. São Paulo: snt., 1995, cap.7, p.47-51.

Sganzerla, E. Nova agricultura: A fascinante arte de cultivar com os plásticos. 6 ed. Porto Alegre: Petroquímica Triunfo, 1995.341p.

Streck, N.A.; Buriol, G.A.; Andriolo, J.L. Crescimento da alface em túneis baixos com filme de polietileno perfurado. Ciência Rural, Santa Maria, v.24, n.2, p.235-240, 1994.

Tanaka, M.; Genta, H. Control del médio ambiente baho invernadero y túnel plástico. Salto: Estación Experimental de Citricultura, 1982. 61p. 